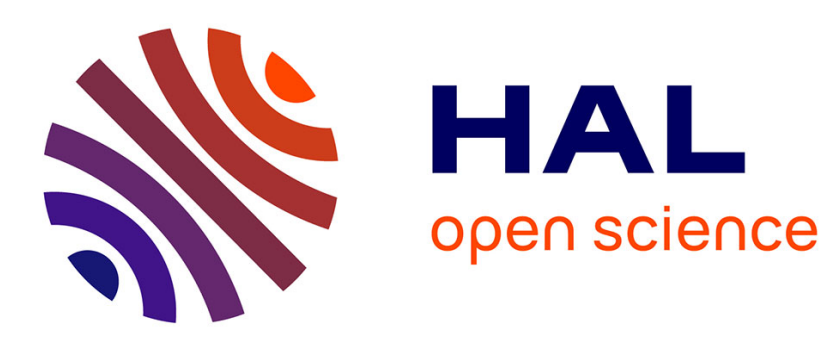

\title{
Designing a contaminated soil sampling strategy for human health risk assessment \\ Laure Malherbe
}

\section{To cite this version:}

Laure Malherbe. Designing a contaminated soil sampling strategy for human health risk assessment. Eurolab/Eurachem International Workshop "Sampling", Nov 2001, Lisbonne, Portugal. ineris00972242

HAL Id: ineris-00972242

https://hal-ineris.archives-ouvertes.fr/ineris-00972242

Submitted on 3 Apr 2014

HAL is a multi-disciplinary open access archive for the deposit and dissemination of scientific research documents, whether they are published or not. The documents may come from teaching and research institutions in France or abroad, or from public or private research centers.
L'archive ouverte pluridisciplinaire HAL, est destinée au dépôt et à la diffusion de documents scientifiques de niveau recherche, publiés ou non, émanant des établissements d'enseignement et de recherche français ou étrangers, des laboratoires publics ou privés. 


\title{
DESIGNING A CONTAMINATED SOIL SAMPLING STRATEGY FOR HUMAN HEALTH RISK ASSESSMENT
}

\author{
L. Malherbe \\ INERIS (Institut National de l'Environnement Industriel et des Risques), Direction des \\ Risques Chroniques, Parc Technologique ALATA, BP 2, 60550 Verneuil-en-Halatte, \\ tel : + $33(0) 3445562$ 18, fax : + 33 (0)3 445568 99, E-mail : laure.malherbe@ineris.fr
}

\section{Introduction - Human health risk assessment : stakes of a relevant soil sampling strategy?}

Human health risk assessment is a site-based approach which provides a decision support in the framework of brownfield sites management. It is aimed at determining if an old site contamination may have harmful effects on human health in view of the planned or current use of the site. If need be it can help to formulate a remediation strategy compatible with that use.

In practice human health risk assessment commonly involves four steps [5] :

1. Site characterization: data providing appropriate information for exposure assessment are collected (nature and extent of contamination, historical review of the site and its users, knowledge of hydrogeology...). Soil sampling comes at that stage.

2. Exposure assessment : the type and magnitude of exposure to chemicals of potential concern present at or migrating from the site are estimated according to (future) land occupation. This stage should include : characterization of exposure setting, identification of exposure pathways, quantification of exposure.

3. Toxicity assessment : qualitative and quantitative toxicity information about substances being evaluated is gathered. This is accomplished in two steps : hazard identification and dose-response assessment.

4. Risk characterization: it brings the toxicity/potency and the exposure data together into an expression of quantitative risk estimation for all receptors.

Obviously the results of risk assessment and the decisions that may ensue are closely dependent on site characterization. This is why a proper soil sampling is of major importance as it can have consequences in terms of public safety and of costs (remediation expenses).

Therefore soil sampling needs to fit the objectives of the study and to follow a well-defined strategy. This includes the number of sampling points, their location on site, the depth and the type of samples to be taken. A sampling strategy for health risk assessment is not necessarily intended to locate hot spots as a preliminary site investigation usually is nor to allow the calculation of contaminated soil volumes as required by a soil cleaning project. It should help to evaluate soil concentrations of toxic compounds in the soil compartments involved in people exposure. Besides it must reconcile scientific requirements with resource constraints.

No sampling strategy has been entirely formalized for human health risk assessment yet. National or international guidelines or standards, such as ISO 10381 provide guidance which is often dictated by the suspected level of contamination rather than by the aim of the study. Thus the site assessor has to adapt those guidelines to the specific problem he is in charge of.

The following study is focused on the designing of a soil sampling strategy for human health risk assessment. It does not handle the specific matter of sampling techniques, sample preparation and chemical analysis. We propose to review the components of a soil sampling strategy and to comment them from the angle of human health risk assessment. For each 
component we will compare several alternatives outlining their advantages and drawbacks. A few examples derived from current practice will be given as an illustration and some recommendations be voiced. The question of a multistage sampling strategy and the problem of representativeness will be briefly discussed.

\section{Which soil sampling strategy for human health risk assessment ?}

\subsection{Sampling pattern : statistical (probabilistic) vs non statistical approaches}

Among the wide range of possible schemes the well-known systematic grid sampling is commonly used in North-America (USA, Canada). A $25 \mathrm{~m}$ grid as recommended by CCME ${ }^{1}$ [2] ensures a complete site coverage and a homogeneous distribution of samples over the site, hence minimizing bias in the estimation of mean concentrations. In a systematic sampling plan every part of the site is equally viewed as a potential exposure area. The likelihood of missing the presence of contamination is thus decreased.

Besides collected data can be treated with statistical and geostatistical tools, the latter leading to a better understanding of contamination spatial variability and providing 2 or 3D-maps of estimated concentrations. The production of such maps rather applies to the devising of soilcleaning projects. However it can bring out possible high-risk areas or unsufficiently sampled areas where the uncertainty on the estimated concentrations might be critical as regards risk evaluation. If the probability of exceeding threshold values is desired then geostatistical techniques such as conditional simulation can be used [6].

Though easy to implement in the field systematic sampling can require a large number of samples and be relatively costly unless it is reduced to a loose mesh grid. If so highly contaminated areas may be poorly characterized and the advantages of systematization invalidated.

This is why non probabilistic strategies directly derived from the suspected pollution may prove relevant too. Judgment sampling in areas assumed representative of the whole site should be banned however because of bias imposed by the investigator's subjectivity. Purposive sampling (fig.1a) consists in selecting sample locations in regions known to be most contaminated in view of the site history. A few samples may be taken in the remaining part of the site for control only. Before opting for such a strategy the assessor should wonder whether average concentrations, percentiles or extreme values are of concern. The answer depends upon the approach he decides to favour : a reasonably conservative or a maximising one. In the first case a targeted sampling is not sufficient to calculate mean concentrations or percentiles. In the second case it could be appropriate providing that hotspots have already been properly located through a thourough exploratory phase. If not it may provide misleading information about site contamination entailing a wrong or incomplete risk assessment.

Another approach designated as stratified random sampling is sometimes advocated (e.g.. in Germany or the Netherlands [1][5]). It combines a pollution-oriented and a statistical random sampling (fig. 1b). The site is first divided into several areas and/or layers (horizontal and vertical strata respectively) in which pollution is supposed to be relatively homogeneous. Each stratum is then randomly sampled. This approach needs a preliminary detailed study but it helps to evaluate contamination spatial variability within and between strata and to improve the precision of the estimated mean concentrations.

\footnotetext{
${ }^{1}$ Canadian Council of the Ministries of the Environment
} 
Some advice can be drawn from this discussion as regards the choice of a sampling pattern. In addition to a purposive sampling scheme a systematic grid sampling (e.g. a square grid) may give a large amount of information about pollution and be rather easily implemented (fig. 1c). To limit costs sampling density (the mesh size) can be adapted to the suspected level of contamination and exposure being increased in heavily contaminated or heterogeneous areas or even in cleaner areas likely to be highly frequented. A preliminary stratification of the site seems particularly adequate for large and complex sites where a uniform sampling strategy could either be costly (too many samples) or mask some features of contamination (too loose a grid) and make the conclusions of risk assessment unreliable. A sampling strategy as described above might then be designed for each stratum separately.
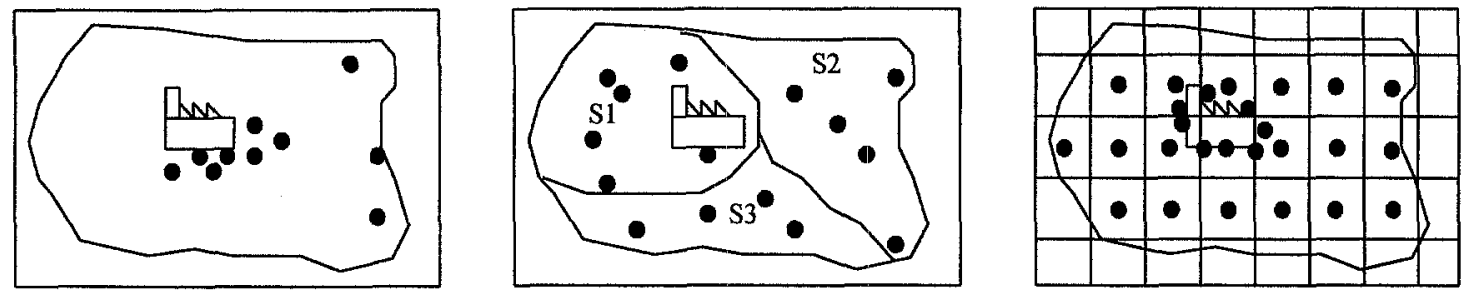

Fig.1a, 1b, 1c : targeted, random stratified, and combination of targeted and systematic sampling (after Pellet \& al. [8])

\subsection{Sample type : grab or composite samples?}

The choice between grab or composite samples can be dictated by soil and contaminants properties and by the analysis costs as well.

A grab sample is an individual sample collected from a single location at a specific time [11]. The collection of grab samples is the best way to get information about the spatial (both lateral and vertical) variability of contamination.

A composite sample is made of a series of discrete equal specimens (aliquots) taken at one location and several depths (vertical composite) or several locations and one depth (spatial composite). It is to be representative of the mean composition of either a vertical profile (vertical composite) or an area (spatial composite). Compositing alliquots reduces the intrinsec variability of the final sample and allows the mean concentration of a profile or an area to be estimated with a better precision. Besides analysis costs are diminished. A composite sample should not however represent an area larger than 1 ha (Jones in [8]) and should be made of more than 4 and less than 9 specimens. With more aliquots concentrations might be diluted [11]. Other technical difficulties are likely to arise when compositing samples (volatilization of some organic compounds, bad homogeneization of humid clay soils) and generate large uncertainties on the analytical results.

So that risk is not underestimated grab samples should be preferred in any circumstances to spatial composites unless the absence of volatile compound and the homogeneity of contamination are really well known. The collection of vertical composites should be avoided too (cf. §2.3.).

It is also necessary to take background samples in areas thought to be free of contaminants. They can tell if site concentrations are higher than those observed in natural background conditions and help the assessor to propose realistic clean-up levels if he is asked to.

\subsection{Sampling depth}

The depths at which samples should be taken are linked to the vertical variability of concentrations. They depend on :

- the soil stratigraphy ; 
- the soil nature and properties which may have an effect on the chemical form and the mobility of contaminants ;

- the soil nature and properties which may have an effect on the chemical form and the mobility of contaminants ;

- the physical and chemical properties of contaminants likely to influence their mobility ;

- the site use and the potential exposure ways.

Thus samples can be taken in the upper layer (over the first centimeters) and/or in subsurface (up to one or several meters depth). Since a contamination profile can be quite uneven it is often recommended to take samples at regular intervals (e.g. every $50 \mathrm{~cm}$ or $1 \mathrm{~m}$ ) and in each stratigraphy unit. Only a few specimens may be then selected for laboratory analysis. The most relevant sampling depths are a function of exposure routes as indicated in table 1.

Table 1. Example of an old industrial site which is to be redeveloped into a residential area

\begin{tabular}{|l|l|l|}
\hline Soil composition & \multicolumn{1}{|c|}{ Depths to be sampled } & Exposure routes \\
\hline $\begin{array}{l}\text { coarse-medium } \\
\text { sand with sandy } \\
\text { loam soil }\end{array}$ & $0-5 \mathrm{~cm}$ & $\begin{array}{l}\text { Soil ingestion, dermal contact with soil and dust, inhalation of contaminated dust, if soil } \\
\text { is not to be paved, and inhalation of volatile compounds. }\end{array}$ \\
& $\begin{array}{l}\text { Soil ingestion, dermal contact and inhalation of contaminated dust (mostly during } \\
\text { gardening activities and children games), ingestion of grown vegetables, if soil is not to } \\
\text { be paved, and inhalation of volatile contaminants. }\end{array}$ \\
\hline silt & $\begin{array}{l}\text { Inhalation of volatile compounds } \\
\text { clay }\end{array}$ & \begin{tabular}{l} 
Inhalation of volatile compounds \\
\hline
\end{tabular} \\
\hline
\end{tabular}

\subsection{Sampling size}

Actually the assessor has to define :

- the number of sampling points to be distributed over the site;

- the number of samples to be taken at each of those points ;

According to the on-site observations made during the investigations he might then reconsider the total number of samples to be analyzed.

The number of samples at each point is linked to the number of selected depths for sampling. As for the number of sampling points litterature shows many recommendations which will not be detailed here. They are based either on experience or on statistics. In the first case they strongly depend on the type of contamination : non suspected, heterogeneous or diffuse contamination. The use of statistics is more of an Anglo-Saxon approach. Determinant factors are then :

- the probability of success in hitting a hot-spot [9].;

- the precision on the mean that the assessor intends to reach [3][12];

- the cost not to be exceeded [3].

The first criterium can be relevant when no prior information about the location of past industrial activities and the soil contamination is available. Otherwise the last two criteria should be preferred: the one allows the site assessor to have a better control over the uncertainties on the calculated risk, the other allows him to integrate cost constraints into the sampling strategy. However the mathematical equations used for determining sampling size assume that concentration variability (expressed by the variation coefficient) is known, which is scarcely the case unless a first sampling stage has been carried out.

This is why we suggest that the assessor use all or part of those recommendations and formulas as an indicative basis, making assumptions about contamination variability if need be, and then adapt the number of samples to the site-specific constraints.

After samples have been taken and analyzed, and variability has been estimated he may appreciate the relevancy a posteriori of his strategy. 


\section{Single or multi-stage sampling ? Complementary methods of investigation}

The formulation of a suitable sampling strategy is made easier by a prior knowledge of site characteristics and soil contamination. A two- or multi-stage sampling is often recommended so that sampling strategy can be refined and improved at each step. This idea shows through the assessment processes developped in Europe and North-America. In France a simplified risk assessment based on a first site inspection (initial diagnostic) normally precedes a detailed risk assessment which requires a detailed diagnostic. In Germany and in the Netherlands a distinction is made between an oriented investigation which provides a general characterization of contamination and a further investigation which should give all necessary information for environment and human health risk assessment [1][4]. A third stage (remediation investigation) is devoted to site redevelopment. In the same way risk assessment in Québec is the result of three steps: the review of all available information (stage I), a preliminary characterization (stage II) and an exhaustive characterization (stage III).

As a counterpart a multi-stage sampling strategy requires time and money. To limit sampling to what is strictly needed the assessor should first look into any available information he can have at his disposal : indications about the past activities of the site and possible soil reworking, visual signs of contamination, results of less expensive field screening techniques. All those indicators ought to be integrated into a conceptual model of contamination. It must be kept in mind that screening methods may be used as a support for sampling but on no account as a substitute because they are only of a qualitative nature.

\section{Sampling error, the problem of representativeness}

A sample should be representative i.e. reflect the properties of the soil volume from which it has been extracted. However representativeness is spoilt by sampling and preparation errors. The results of a « comparative evaluation of European methods for sampling and sample preparation of soils for inorganic analysis » [13] demonstrate that sampling and sample preparation errors can reach about the same order of magnitude as errors caused in the chemical analysis. Their relative contribution to the total uncertainty in soil contamination studies (and consequently in the assessed risk) is more a subject of speculation than of knowledge even if assurance and control quality (ACQ) sampling aid in quantifying them. However the assessor can take some precautions to reduce such errors, for example by increasing the sampled volume when soil granulometry is heterogeneous.

\section{Conclusion}

Soil sampling of a contaminated site is an essential means of collecting qualitative and quantitative data for estimating people exposure. A cost-efficient sampling plan should be developed with respect to the historical, geological and geochemical conditions on the one hand and the current or planned land utilization on the other hand. Guidance exists on that subject but no sampling strategy has been entirely formalized for human health risk assessment. Given all the constraints the assessor has to cope with, a few recommendations seem more appropriate than the enforcement of a rigid strategy.

A non probabilistic sampling dictated by an initial knowledge of contamination may fit the actual situation of burden at the site but lead to an under or overestimation of concentrations. A statistical approach such as grid sampling ensures a complete coverage of the site but it could induce useless sampling. In fact both methods can be combined. The assessor should thouroughly study all available information (site and soil properties, physical characteristics of contaminants, results of previous investigations...) so as to delimit homogeneous contaminated 
areas and distribute the sampling points at best in each of them (e.g. using a sampling grid and adapting sampling density to the suspected level and the heterogeneity of contamination and to the precision he intends to reach). He should also take the (future) use of the site into account in order to define areas and layers to be sampled as a priority. Statistical and geostatistical tools can be helpful for constructing of a sampling strategy as well as for the analysis of the collected data.

\section{References}

[1] Bosman, R., Lamé, F.P.J., 1990. Systematische Probenahmestrategien für die Untersuchung der Scahdstoffbelastung von Boden und Porenwasser. Ed. W.J, van den Brink, R. Bosman and F. Arendt, Altlastensanierung '90, 837-839.

[2] CCME, 1993. Guide pour l'échantillonnage, l'analyse des échantillons et la gestion des données des lieux contaminés.

[3] Gilbert, R. O., 1987. Statistical Methods for Environmental Pollution Monitoring. Ed. Van Nostrand Reinhold Company, NY.

[5] Hortensius, D., Bosman, R., Harmsen, J. und Wever, D., 1990. Entwicklung standardisierter Probenahmestrategien für Bodenuntersuchungen in den Niederlanden. Ed. W.J. van den Brink, R. Bosman and F. Arendt, Altlastensanierung '90, 795-804.

[4] MATE, INERIS, BRGM, 2000. Guide Gestion des Sites Pollués : Diagnostic approfondi - Evaluations détaillées des Risques. Ed. BRGM.

[6] Nathanail, P., Ferguson, C., Brown, M.J., and Hooker, P.J., 1998. A geostatistical approach to spatial risk assessment of lead in urban soils. Proceedings of the 8th International Congress, International Association for Engineering Geology and the Environment, 21-25 sept. 1998, Vancouver, Canada.

[7] Pellet, M., Laville-Timsit, L., décembre 1993. Echantillonnage de sols pour caractérisation d'une pollution: guide méthodologique. Ministère de l'Environnement, rapport BRGM, Service géologique national.

[8] Tan, K.H., 1995. Soil Sampling, Preparation and Analysis. Ed. Marcel Dekker, NY, USA.

[9] Tucker, P., Ferguson, C., Abbachi, A., and Nathanail, P., 1996. A decision support system for designing sampling strategies for potentially contaminated sites. Proceedings of the 7th International Symposium on Spatial Data Handling, SDH 96, Delft, The Nehtherlands, 12 - 16 August.

[10] U.S. EPA (Mason, B.J.), 1992. Preparation of Soil Sampling Protocols : Sampling Techniques and Strategies. (http://www.epa.gov/swerust1/cat/mason.pdf)

[11] U.S EPA, 1996 (revised in 1997), Environmental Investigations Standard Operating Procedures and Quality Assurance Manual, Section 5: Sampling design and quality assurance procedures, Section 12: Soil sampling.

[12] U.S. EPA, 2000, Guidance for Choosing a Sampling Design for Environment Data Collection, Use in the Development of a Quality Assurance Project Plan, Peer review draft.

[13] Wagner G., Mohr, M.-E, Sprengart, J., Desaules, A., Muntau, H., Theocharopoulos, S, and Quevauviller, P., 2001. Objectives, concept and design of the CEEM soil project, The Science of The Total Environment, Volume 264, Issues 1-2, 3-15. 